urine. Subsequently he became confused and disorientated. On examination his temperature was found to be $37.8^{\circ} \mathrm{C}$ and he was jaundiced and drowsy, with petechiae on arms, legs, and trunk. Haemoglobin concentration was $9.0 \mathrm{~g} / \mathrm{dl}$, white cell count $5.0 \times 10^{9} / \mathrm{l}$, and platelets $<10 \times 10^{\circ} / 1$, and the blood film showed pronounced redcell fragmentation. Urine analysis showed heavy proteinuria and haematuria. He was treated with fresh-frozen plasma, hydrocortisone $200 \mathrm{mg}$ six-hourly intravenously, heparin $1000 \mathrm{IU} / \mathrm{h}$, and intravenous dipyridamole $100 \mathrm{mg}$ with no clinical or haematological improvement. He became comatose shortly after arrival and died two days after admission. Permission for necropsy was refused.

\section{Methods and results}

Plasma samples were collected from the two patients before treatment and from 22 healthy male and female laboratory staff and stored at $-30^{\circ} \mathrm{C}$ until assayed. Samples were buffered to $\mathrm{pH} 4.0$ and prostaglandins extracted with ethyl acetate. Extracts were measured by radioimmunoassay for 6-oxo- $\mathrm{PGF}_{1} \alpha^{4}$ and thromboxane $\mathrm{B}_{2}$. The method for thromboxane $\mathbf{B}_{2}{ }^{5}$ was modified, antibody-bound thromboxane $B_{2}$ being extracted by using donkey antirabbit IgG precipitating serum (Scottish Antibody Production Unit). The mean recovery from the extraction procedure, established with ${ }^{3} \mathrm{H}-6-\mathrm{oxo}-$ $\mathrm{PGF}_{1 \alpha}$ and ${ }^{3} \mathrm{H}$-thromboxane $\mathrm{B}_{2}$ (New England Nuclear) as tracers, was $95 \pm$ SD $3 \%$ and $94 \pm 1 \%(n=5)$ for 6 -oxo-PGF $1 \alpha$ and thromboxane $B_{2}$, respectively. Interassay and intra-assay coefficients of variation were $2 \cdot 0 \pm 0 \cdot 1 \%$ and $3 \cdot 1 \pm 0 \cdot 2 \%$, respectively, for 6-oxo$\mathrm{PGF}_{1 \alpha}$, and $10.7 \%$ and $12 \cdot 1 \%$, respectively, for thromboxane $B_{2}$. The table shows the values recorded.

\section{Comment}

Occasional remissions have been reported in thrombotic thrombocytopenic purpura with various forms of treatment, ${ }^{6}$ but our two patients failed to respond to several forms of treatment, including an infusion of $\mathrm{PGI}_{2}$ in case 1 . The plasma concentrations of 6 -oxo- $\mathrm{PGF}_{1} \alpha$ and thromboxane $\mathrm{B}_{2}$ were
Plasma concentrations of 6-oxo-PGF $1_{1^{a}}$ and thromboxane $B_{2}$ in cases 1 and 2 and 22 healthy subjects

\begin{tabular}{|c|c|c|c|c|}
\hline & \multirow{2}{*}{ Case 1} & \multirow{2}{*}{ Case 2} & \multicolumn{2}{|c|}{ Healthy subjects } \\
\hline & & & Range & Mean $\pm \mathrm{SD}$ \\
\hline $\begin{array}{l}\text { 6-oxo-PGF } 1 a(\mu \mathrm{g} / \mathrm{l}) \\
\text { Thromboxane } \mathrm{B}_{2}(\mu \mathrm{g} / \mathrm{l})\end{array}$ & $\begin{array}{l}0.83 \\
5.90\end{array}$ & $\begin{array}{l}0 \cdot 80 \\
4 \cdot 10\end{array}$ & $\begin{array}{l}0 \cdot 16-0.83 \\
0 \cdot 15-13 \cdot 80\end{array}$ & $\begin{array}{c}0.50 \pm 0 \cdot 17 \\
2 \cdot 62^{*}\end{array}$ \\
\hline
\end{tabular}

*Geometric mean of skewed distribution.

normal in both patients, implying that amounts of the circulating precursor compounds $\mathrm{PGI}_{2}$ and thromboxane $\mathrm{A}_{2}$ were also normal. In these two patients we therefore did not find the deficiency of $\mathrm{PGI}_{2}$ that has been suggested as a factor in the pathogenesis of thrombotic thrombocytopenic purpura, though we cannot comment on the rate of $\mathrm{PGI}_{2}$ degradation. We conclude that 6-oxo-PGF $F_{1}$ is detectable and may be in normal concentration in thrombotic thrombocytopenic purpura and that this condition need not be associated with a high concentration of thromboxane $A_{2}$.

\section{References}

1 Hensby CN, Lewis PJ, Hilgard P, Mufti GJ, Hows J, Webster J. Prostacyclin deficiency in thrombotic thrombocytopenic purpura. Lancet 1979 ;ii:748.

2 Machin SJ, Defreyn G, Chamone DAF, Vermylen J. Plasma 6-keto$\mathrm{PGF}_{1^{a}}$ levels after plasma exchange in thrombotic thrombocytopenic purpura. Lancet 1980; i:661.

${ }^{3}$ Chen YC, McLeod B, Hall E, Wu KK. Accelerated prostacyclin degradation in thrombotic thrombocytopenic purpura. Lancet 1981 ;ii:267-9.

1 Dighe KK, Jones RL, Poyser NL. Development of a radioimmunoassay for measuring 6-oxo-prostaglandin $\mathrm{F}_{1 a}$. Br 7 Pharmacol 1978;63:406.

${ }^{5}$ Salmon JA. A radioimmunoassay for 6-keto-prostaglandin $\mathrm{F}_{1 \mathrm{a}}$. Prostaglandins 1978;15:383-97.

6 Amorosi EL, Karpatkin S. Antiplatelet treatment of thrombotic thrombocytopenic purpura. Ann Intern Med 1977;86:102-6.

(Accepted 22 September 1981)

\title{
A relation between high-density-lipoprotein cholesterol and bile cholesterol saturation
}

\author{
J R THORNTON，K W HEATON，D G MACFARLANE
}

\begin{abstract}
The association of cholesterol gall stones with coronary artery disease is controversial. To investigate this possible relation at the biochemical level, bile cholesterol saturation and the plasma concentrations of triglycerides, total cholesterol, and high-density-lipoprotein cholesterol (HDL cholesterol) were measured in 25 healthy, middleaged women. Bile cholesterol saturation index was negatively correlated with HDL cholesterol. It was positively correlated with plasma triglycerides and with total cholesterol minus HDL cholesterol.

These findings provide a biochemical basis for a positive association in women between cholesterol gall stones and coronary artery disease.

\footnotetext{
University Department of Medicine, Bristol Royal Infirmary, Bristol BS2 8HW

J R THORNTON, MRCP, honorary senior registrar

$\mathrm{K}$ W HEATON, MD, FRCP, reader in medicine

D G MACFARLANE, MRCP, lecturer
}

\section{Introduction}

The association of cholesterol gall stones with coronary artery disease is controversial. Some early necropsy studies showed an increased prevalence of gall stones in patients with severe coronary artery disease ${ }^{1}$ and in patients who had died of myocardial infarction, ${ }^{23}$ whereas another study did not find any definite relation. ${ }^{4}$ Later epidemiological studies were also conflicting, showing, in women, both positive ${ }^{5}$ and negative associations.

A way to investigate the association may be to look for correlations between plasma and biliary lipid concentrations. Conceivably, a low concentration of high-density-lipoprotein cholesterol (HDL cholesterol) might underlie and explain a positive association between ischaemic heart disease and cholesterol gall stones. Cholesterol is kept in solution in bile by the action of bile acids and phospholipids. If the cholesterol excreted into bile exceeds this solubilising capacity, bile becomes supersaturated with cholesterol and apt to precipitate gall stones. ${ }^{7} \mathrm{HDL}$ cholesterol is an important protective factor against coronary artery disease. ${ }^{8-11}$ The cholesterol taken up by high-density lipoprotein is believed to be excreted in bile ${ }^{12} 13$ 
but it is not known whether it is excreted as such or after conversion to bile acids.

We have examined some relations between bile cholesterol saturation, on the one hand, and the plasma concentration of HDL cholesterol and other plasma lipids, on the other.

\section{Subjects and methods}

Thirty healthy women volunteered for the study. To minimise possible variation in plasma and biliary lipid concentrations due to age and body fatness, we selected only women aged 40-45 years and who were 100-110" "of ideal body weight. None was taking any medication, including oral contraceptives. All had normal standard liver function values. Oral cholecystography was omitted on ethical grounds, but no subject had symptoms suggestive of gall-bladder disease. Three of the women were found to have hyperlipidaemia and were excluded. Two others were excluded because their bile samples were too weak for accurate analysis (total lipid concentration less than $20 \mathrm{mmol} / \mathrm{l}$. To avoid possible fluctuations in bile and plasma lipid concentrations related to the menstrual cycle $^{14}$ samples were collected within the first five days of each woman's cycle.

Subjects abstained from drinking alcohol for one week before testing. After an overnight fast bile and venous blood were sampled simultaneously. Bile-rich duodenal fluid was collected after duodenal intubation and intravenous injection of cholecystokinin. This elicited a prompt flow of concentrated bile in all cases. The composition of bile thus obtained reflects accurately that of gall-bladder bile. ${ }^{15}$

Total bile salt, phospholipid, and biliary cholesterol concentrations were measured. ${ }^{16}$ Individual bile acid composition was determined by gas-liquid chromatography. Bile cholesterol saturation index was calculated by the method of Thomas and Hofmann ${ }^{17}$ using the criteria of Hegardt and Dam. ${ }^{18}$ Plasma cholesterol ${ }^{19}$ and triglyceride ${ }^{20}$ concentrations were measured by routine autoanalyser methods. HDL cholesterol was measured by a manual cholesterol oxidase method (Boehringer Mannheim GmbH 236691) after precipitation of the other lipoproteins with heparin and manganese chloride. ${ }^{21}$ The statistical significance of correlation coefficients was determined by Student's $t$ test.

\section{Results}

Mean bile cholesterol saturation index was $1.09+$ SEM $0 \cdot 15$, and 18 of the 25 women had supersaturated bile. Mean plasma lipid values were: plasma triglycerides $0.73: 0.21 \mathrm{mmol} / 1(64.6: 18.6 \mathrm{mg} /$ $100 \mathrm{ml})$, total plasma cholesterol $4.98 \quad 0.90 \mathrm{mmol} / 1(192.3 .34 .7 \mathrm{mg} /$ $100 \mathrm{ml})$, and HDL cholesterol $1.58: 0.25 \mathrm{mmol} / 1(61.0 \div 9.7 \mathrm{mg} / 100$ $\mathrm{ml})$.

Bile saturation index was positively correlated with plasma triglyceride concentration $(r=0.471 ; p<0.02 ;$ fig 1$)$ but not with total plasma cholesterol concentration $(r=0.319$; NS). Saturation index was negatively correlated with HDL cholesterol $(r=-0.509$; $\mathrm{p}<0.01 ;$ fig 2 ). There was no significant correlation between HDL cholesterol and plasma triglycerides $(r=-0 \cdot 346)$. The association of HDL cholesterol and plasma triglycerides with bile cholesterol

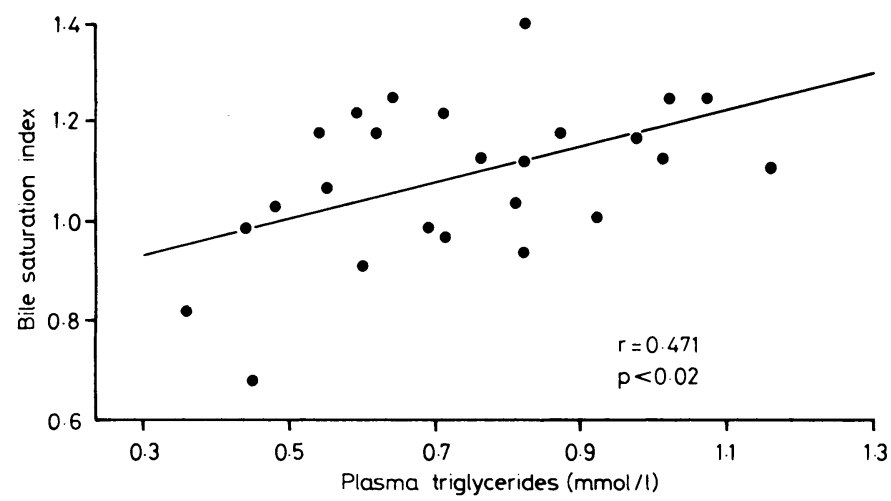

FIG 1-Correlation of bile cholesterol saturation index and plasma triglyceride concentration in 25 normolipidaemic women.

Conversion: SI to traditional units-Triglycerides: $1 \mathrm{mmol} / 1 \approx 88.5 \mathrm{mg}$ / $100 \mathrm{ml}$.

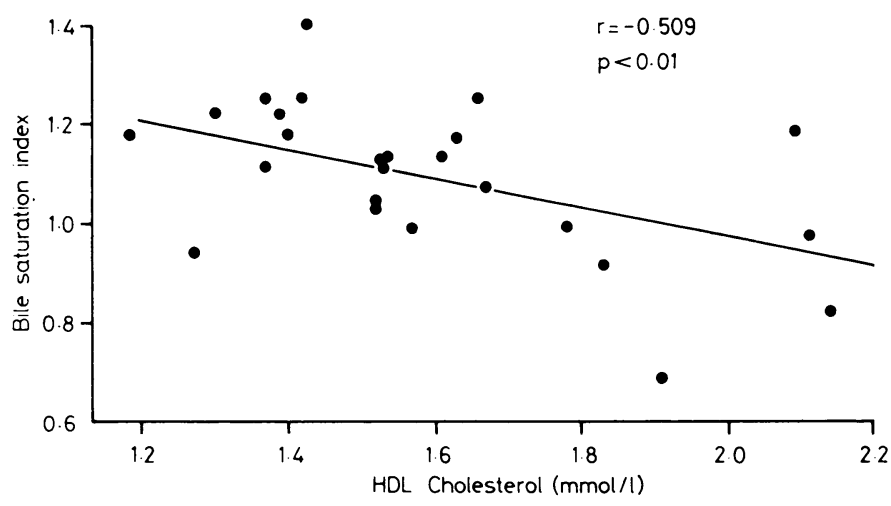

FIG 2-Correlation of bile cholesterol saturation index and HDL cholesterol concentration in 25 normolipidaemic women.

Conversion: SI to traditional units-HDL cholesterol: $1 \mathrm{mmol} / 1 \approx 38.6$ $\mathrm{mg} / 100 \mathrm{ml}$.

saturation was shown by multivariate analysis to be partially independent.

HDL cholesterol was subtracted from total cholesterol to give a measure of the cholesterol contained in low-density lipoprotein and very-low-density lipoprotein. This value showed a significant positive correlation with bile saturation index ( $r=0.597 ; \mathrm{p}<0.005$; fig 3). No significant correlations were found between the proportions of the individual bile acids with the various plasma lipids.

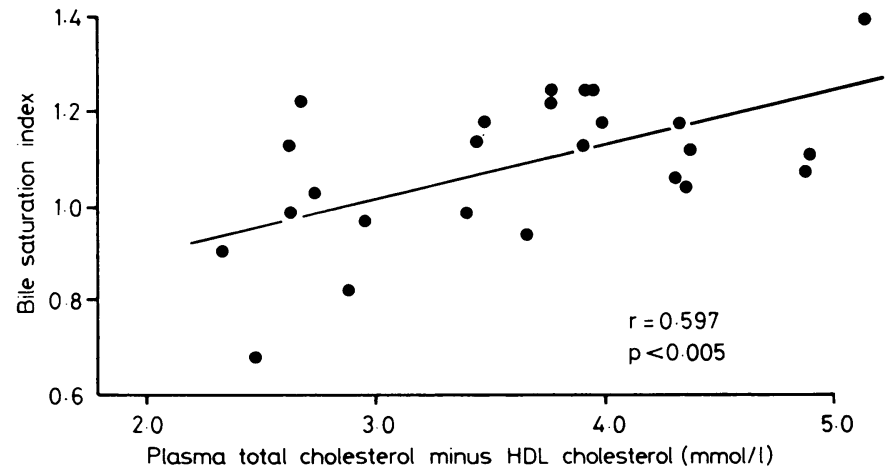

FIG 3-Correlation of bile cholesterol saturation index and plasma concentration of total cholesterol minus HDL cholesterol in 25 normolipidaemic women.

Conversion: SI to traditional units-Cholesterol and HDL cholesterol: $1 \mathrm{mmol} / 1 \approx 38.6 \mathrm{mg} / 100 \mathrm{ml}$.

\section{Discussion}

This study shows that in healthy middle-aged women bile cholesterol saturation is inversely correlated with the plasma HDL cholesterol concentration. This is consistent with a recent report that women with a history of gall-bladder disease have a reduced concentration of $\mathrm{HDL}$ cholesterol. ${ }^{22}$

We have also shown that a relation exists between bile cholesterol saturation and plasma triglycerides, not only in hypertriglyceridaemia ${ }^{23}$ but also when the triglyceride concentration is normal. Plasma triglycerides are transported by very-low-density lipoprotein, which is catabolised with the removal of triglyceride to low-density lipoprotein ${ }^{24}{ }^{25}$; this lipoprotein carries most of the plasma cholesterol, the remainder being transported by high-density lipoprotein. High-density lipoprotein is thought to facilitate the egress of cholesterol from atheromatous plaques ${ }^{26}{ }^{27}$ and inhibit tissue uptake of cholesterol from low-density lipoprotein. ${ }^{28}$ If the cholesterol taken up and transported to the liver by high-density lipoprotein is secreted into bile wholly or predominantly as cholesterol, then high concentrations of high-density lipoprotein might be envisaged as increasing the risk of gall stones. Conversely, if $\mathrm{HDL}$ 
cholesterol is converted to bile acids, then a high concentration of the lipoprotein, in addition to being antiatherogenic, might also protect against gall stones.

It has been suggested that bile acids and biliary cholesterol are derived from separate hepatic pools of cholesterol ${ }^{29}$ and that these pools are derived mainly from lipoproteins, rather than newly synthesised cholesterol. ${ }^{30} \mathrm{High}$-density lipoprotein has been proposed as the main lipoprotein contributor to both these pools ${ }^{12}{ }^{13}$-but on the basis of experiments in a single patient. The inverse correlation of HDL cholesterol and bile cholesterol saturation throws doubt on the suggestion ${ }^{12}$ that cholesterol from high-density lipoprotein is an important source of biliary cholesterol. Low-density lipoprotein, ${ }^{31}$ like high-density lipoprotein, ${ }^{26}$ may have an important role in returning cholesterol to the liver. The positive correlation of bile cholesterol saturation with total plasma cholesterol minus HDL cholesterol (largely low-density lipoprotein cholesterol) might indicate that biliary cholesterol is derived principally from low-density lipoprotein.

As to whether cholesterol derived from high-density lipoprotein is converted to bile acids, ${ }^{13}$ the inverse correlation of bile cholesterol saturation and HDL cholesterol would be compatible with this idea. From our data, however, we cannot comment on whether HDL cholesterol is the sole or even the main contributor of the cholesterol utilised for bile acid synthesis.

The data suggest that measures which alter HDL cholesterol concentration, either beneficially-for example, exercise, ${ }^{32-34}$ moderate alcohol consumption ${ }^{34} 35$-or detrimentally-for example, cigarette smoking ${ }^{34}$-may have similar, as yet unreported effects on the cholesterol saturation of bile.

In conclusion, our findings disclose a relation in women between a major risk factor for ischaemic heart disease and the metabolic basis of cholesterol cholelithiasis. The data provide a biochemical basis for a positive association between gall stones and coronary artery disease.

This study was supported by a grant from the Medical Research Council.

We acknowledge the help in recruiting volunteers of the following doctors of the Whiteladies Health Centre, Bristol: Dr M J Whitfield, Dr T F Paine; Dr C Harris, and Dr R W Heath.

\section{References}

1 Tennant R Jr, Zimmerman HM. Association between disease in the gallbladder and in the heart, as evidenced at autopsy. Yale $\mathcal{f}$ Biol Med $1931 ; 3: 495-503$.

${ }^{2}$ Breyfogle HS. The frequency of coexisting gallbladder and coronary artery disease: a statistical analysis and biometric evaluation of 1,493 necropsies. F $A M A$ 1940;114:1434-7.

3 Watkinson $G$. Relationship between gallstones and other medical diseases. In: Ueda $\mathrm{H}$, ed. Proceedings of third world congress on gastroenterology. Basle: Karger, 1967;4:125-30.

4 Sternby NH. Atherosclerosis in a defined population. An autopsy study in Malmo, Sweden. Acta Pathol Microbiol Scand 1968;suppl 194:136-42.

5 Petitti DB, Wingerd J, Pellegrin F, Ramcharan S. Risk of vascular disease in women. Smoking, oral contraceptives, noncontraceptive estrogens and other factors. F $A M A 1979 ; 242: 1150-4$

6 Barker DJP, Gardner MJ, Power C, Hutt MSR. Prevalence of gallstones at necropsy in nine British towns: a collaborative study. $\mathrm{Br} \mathrm{Med} \mathrm{f}$ 1979 ;ii : $1389-92$.

${ }^{7}$ Carey MC, Small DM. The physical chemistry of cholesterol solubility in bile. Relationship to gallstone formation and dissolution in man. f Clin Invest $1978 ; 61$ :998-1026.

8 Castelli WP, Doyle JT, Gordon T, et al. HDL cholesterol and other lipids in coronary heart disease. The Cooperative Lipoprotein Phenotyping Study. Circulation 1977;55:767-72.

${ }^{9}$ Rhoads GG, Gulbrandsen CL, Kagan A. Serum lipoproteins and coronary heart disease in a population study of Hawaii Japanese men. $N$ Engl f Med 1976;294:293-8.

${ }^{10}$ Miller NE, Førde OH, Thelle DS, Mjøs OD. The Tromsø heart study. High density lipoprotein and coronary heart disease: a prospective case-control study. Lancet $1977 ; \mathrm{i}: 965-8$.

11 Gordon T, Castelli WP, Hjortland MC, Kannel WB, Dawber TR. High density lipoprotein as a protective factor against coronary heart disease. Am $\mathcal{F}$ Med 1977;62:707-14.
12 Schwartz CC, Halloran LG, Vlahcevic ZR, Gregory DH, Swell L. Preferential utilization of free cholesterol from high-density lipoprotein for biliary cholesterol secretion in man. Science 1978;200:62-4.

${ }^{13}$ Halloran LG, Schwartz CC, Vlahcevic R, Nisman RM, Swell L. Evidence for high-density lipoprotein-free cholesterol as the primary precursor for bile-acid synthesis in man. Surgery 1978;84:1-7.

${ }^{14}$ Low-Beer TS, Wicks ACB, Heaton KW, Durrington P, Yeates J. Fluctuations of serum and bile lipid concentrations during the menstrual cycle. $\mathrm{Br}$ Med $\mathcal{F}$ 1977; i:1568-70.

15 Vlahcevic ZR, Bell CC, Juttijudata P, Swell L. Bile-rich duodenal fluid as an indicator of biliary lipid composition and its applicability to detection of lithogenic bile. Am f Dig Dis 1971;16:797-802.

${ }^{16}$ Bolton CH, Low-Beer TS, Pomare EW, Wicks ACB, Yeates J, Heaton KW. A simplified procedure for the analysis of cholesterol, phospholipids and bile salts in human bile. Clin Chim Acta 1978;83:177-81.

17 Thomas PJ, Hofmann AF. A simple calculation of the lithogenic index of bile: expressing biliary lipid composition on rectangular coordinates. Gastroenterology 1973;65:698-700.

18 Hegardt FG, Dam H. The solubility of cholesterol in aqueous solutions of bile salts and lecithin. $Z$ Ernaehrungswiss 1971;10:223-33.

19 Robertson G, Cramp DG. An evaluation of cholesterol determination in serum and serum lipoprotein fractions by a semiautomated fluorimetric method. F Clin Pathol $1970 ; 23: 243-5$.

${ }^{20}$ Kessler G, Lederer H. Fluorimetric measurement of triglycerides. In: Skeggs LT, ed. Automation in analytical chemistry. Vol 1. New York: Medical Incorporated, 1966:341-4.

${ }^{21}$ Burnstein M, Scholnick HR. Lipoprotein-polyanion-metal interactions. Adv Lipid Res 1973;11:67-82.

22 Pettiti DB, Friedman GD, Klatsky AL. Association of a history of gallbladder disease with a reduced concentration of high density lipoprotein cholesterol. $N$ Engl f Med 1981 ;304:1396-8.

23 Ahlberg J, Angelin B, Einarsson K, Hellstrom K, Leijd B. Biliary lipid composition in normo- and hyperlipoproteinemia. Gastroenterology 1980;79:90-4.

${ }^{24}$ Eisenberg S, Bilheimer DW, Levy RI, Lingren FT. On the metabolic conversion of human plasma very low density lipoprotein to low density lipoprotein. Biochim Biophys Acta 1973;326:361-77.

25 Sigurdsson G, Nicoll A, Lewis B. Conversion of very low density lipoprotein to low density lipoprotein. A metabolic study of apolipoprotein B kinetics in human subjects. F Clin Invest 1975;56:1481-90.

${ }^{26}$ Glomset JA. The plasma lecithin: cholesterol acyl transferase reaction. F Lipid Res 1968;9:155-67.

27 Stein O, Vanderhoek J, Stein Y. Cholesterol content and sterol synthesis in human skin fibroblasts and rat aortic smooth muscle cells exposed to lipoprotein-depleted serum and high density apolipoprotein/phospholipid mixtures. Biochim Biophys Acta 1976;431:347-58.

${ }^{28}$ Carew TE, Koschinsky T, Hayes SB, Steinberg D. A mechanism by which high density lipoproteins may slow the atherogenic process. Lancet $1976 ; \mathrm{i}: 1315-7$.

29 Sodhi HS, Kudchodkar BJ. Correlating metabolism of plasma and tissue cholesterol with that of plasma lipoproteins. Lancet 1973;i:513-9.

${ }^{30}$ Schwartz CC, Berman M, Vlahcevic ZR, Halloran LG, Gregory DH, Swell L. Multicompartmental analysis of cholesterol metabolism in man. Characterization of the hepatic bile acid and biliary cholesterol precursor sites. $\mathcal{F}$ Clin Invest $1978 ; 61: 408-23$.

${ }^{31}$ Sniderman A, Thomas D, Marpole D, Teng B. Low density lipoprotein. A metabolic pathway for return of cholesterol to the splanchnic bed. 7 Clin Invest 1978;61:867-73.

32 Carlson LA, Mossfeldt F. Acute effects of prolonged, heavy exercise on the concentration of plasma lipids and lipoproteins in man. Acta Physiol Scand 1964;62:51-9.

${ }^{33}$ Lopez A, Vial R, Balart L, Arroyave G. Effect of exercise and physical fitness on serum lipids and lipoproteins. Atherosclerosis 1974;20:1-9.

34 Williams P, Robinson D, Bailey A. High density lipoprotein and coronary risk factors in normal men. Lancet $1979 ; \mathrm{i}: 72-5$.

${ }^{35}$ Castelli WP, Doyle JT, Gordon T, et al. Alcohol and blood lipids. The co-operative lipoprotein phenotyping study. Lancet 1977;ii:153-5.

(Accepted 22 September 1981)

PERSONS not fkilled in anatomy ought never to bleed in a vein that lies over an artery or a tendon, if they can avoid it. The former may eafily be known from its pulfation or beating, and the latter from its feeling hard or tight like a whip cord under the finger.

It was formerly a rule, even among thofe who had the character of being regular practitioners, to bleed their patients in certain difeafes till they fainted. Surely a more ridiculous rule could not be propofed. One perfon will faint at the very fight of a lancet, while another will lofe almolt the whole blood of his body before he faints. Swooning depends more upon the ftate of the mind than of the body; befides, it may often be occafioned or prevented by the manner in which the operation is performed.

(Buchan's Domestic Medicine, 1786.) 